Revista "O Teatro Transcende" Departamento de Artes - CCEAL da FURB - ISSN 2236-6644 -

Blumenau, Vol. 26, № 1, p. 159 -172 - (2021)

\title{
O ENSINO DA DANÇA JAZZ EM BRUSQUE - SC: HISTÓRIAS DE UMA HISTÓRIA
}

\author{
Maria Carolina Cavaco ${ }^{1}$ \\ mariacaroldf@gmail.com \\ Marco Aurélio da Cruz Souza ${ }^{2}$ \\ marcoaurelio.souzamarco@gmail.com
}

\section{RESUMO}

Este artigo tem como objetivo apresentar o mapeamento dos atores (sujeitos e espaços formativos) responsáveis pela construção da história do jazz na cidade Brusque (SC) entre os anos 1980 à 2020. Como metodologia procurou-se ouvir por meio de entrevistas semiestruturadas os 8 profissionais mapeados que trabalham com o jazz e diretores dos studios de dança da cidade. Estes relatarem suas vivencias e experiências com a dança jazz e os espaços pelos quais passaram. Buscamos desenvolver um cruzamento de saberes vividos dos participantes, para permitir distintas reflexões e revelar novos conhecimentos. Para melhor compreensão dos dados coletados, foram criadas categorias de análises que são: espaços para realização da dança jazz, profissionais que trabalham com a dança jazz e metodologias utilizadas. Contar histórias de studios e professores de dança, como cada entrevistado ministra e organiza suas aulas, e como fazem sua formação continuada, bem como, o jazz evoluiu na cidade foi um desafio, pois, percebemos que as histórias se interligam umas nas outras, formando 3 gerações de bailarinos e professores.

Palavras-chave: Jazz em Brusque; Espaços para o ensino da dança jazz; Professores de jazz em Brusque.

\section{ABSTRACT}

This article aims to present the mapping of the actors (subjects and formative spaces) responsible for the construction of the history of jazz in the city of Brusque (SC) between 1980 and 2020. As a methodology, we tried to hear the 8 professionals through semi-structured interviews. mapped who work with jazz and dance studio directors in the city. They report their experiences and experiences with jazz dance and the spaces they have passed through. We seek to develop a crossover of knowledge experienced by the participants, to allow for different reflections and reveal new knowledge. A better understanding of the data collected was created, categories of analysis were created, which are: spaces for performing jazz dance, professionals who work with jazz dance and the methodologies used. Telling stories of dance studios and dance teachers was a challenge. We tried to identify how each dance teachers organize their classes, and how they do their continuing education and how jazz evolved in the city. We realized that one of the stories intertwines with each other, forming 3 generations of dancers and teachers.

Key words: Jazz Dance in Brusque; Studios for teaching jazz dance; Jazz teachers in Brusque.

\footnotetext{
${ }^{1}$ Licenciada em Dança da Universidade Regional de Blumenau - FURB. Professora, bailarina e pesquisadora, mora na cidade de Guabiruba - SC.

2 Doutor em Motricidade Humana na especialidade Dança pela Universidade de Lisboa - Portugal, coordenador do curso de Licenciatura em Dança e professor da pós-graduação Especialização em Linguagem e Poéticas da Dança, ambas da Universidade Regional de Blumenau (FURB), membro do conselho científico da Associação Nacional dos Pesquisadores em Dança (2019-2021) e do concelho editorial (2021-2023). Vice-presidente da APRODANÇA - SC (2019-2023).
} 


\section{INTRODUÇÃO}

Mapear significa "expor através de um mapa" ou ainda, "construir ou confeccionar um mapa de algo ou de algum lugar" conforme o Dicionário Online de Português (2009). Neste sentido, mapeamento é a "aplicação do processo cartográfico, sobre uma coleção de dados, com vistas à obtenção de uma representação gráfica da realidade perceptível". (Dicionário Online Michaelis, 2020). É assim que surge este trabalho, na tentativa de conhecer melhor as histórias relacionadas com a dança jazz na cidade de Brusque (SC), a partir de um mapeamento dos sujeitos e espaços formativos em dança.

Este é um assunto de grande interesse dos pesquisadores "a história da dança jazz na cidade de Brusque (SC)", pois uma das autoras mora na cidade de Brusque e tem uma íntima relação com a modalidade seja como bailarina, seja como professora e o outro autor trabalha com a dança no ensino superior na cidade. Sendo assim, pedimos licença ao leitor para uma breve contextualização da trajetória da brusquense Maria Carolina Cavaco com esta dança nos próximos parágrafos, que foram anotadas em seu diário de campo e guardadas em suas memórias afetivas.

Quando pequena, via minhas primas dançarem e sempre estava junto com elas brincando pela casa da minha avó, dando saltos e piruetas.

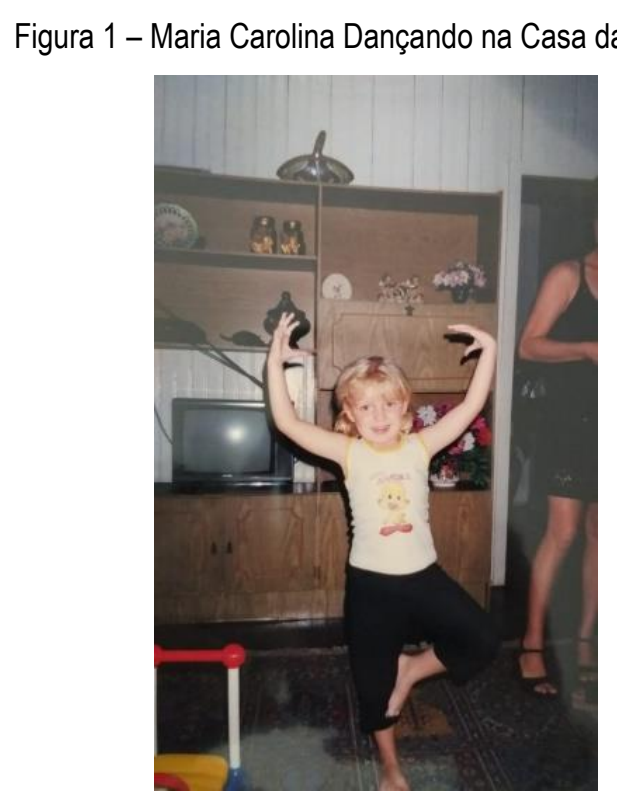

Fonte: acervo pessoal da pesquisadora 
Revista "O Teatro Transcende" Departamento de Artes - CCEAL da FURB - ISSN 2236-6644 -

Blumenau, Vol. 26, № 1, p. $159-172-$ (2021)

Quando completei 3 anos minha mãe me colocou na escola de dança Equilibrio, onde as aulas eram lúdicas e criativas para meninas e meninos desta idade. Logo em seguida do início as aulas, já me destacava entre as alunas no que tange o nível técnico, então, por indicação de minha professora, passei a frequentar uma turma acima da minha. As meninas deste novo grupo eram todas mais velhas que eu. E assim, dancei na academia Equilibrio até meus 7 anos de idade, no ano de 2001, sempre na modalidade de Jazz, até que por motivos econômicos, foi fechada. Foi quando eu passei a frequentar outra instituição da cidade, a Academia Somma, onde permaneci por lá até os meus 16 anos, fazendo aulas de outras modalidades: ballet clássico, dança contemporânea e jazz, que sempre foi minha paixão maior. Estas outras modalidades nos foram indicadas pois os professores indicavam que era a base da dança, e como alunos adolescentes não conhecíamos os termos técnico, acreditávamos e fazíamos.

A figura 2 mostra a sua participação no papel de Clara no espetáculo "O Quebra Nozes", que aconteceu no antigo anfiteatro da Unifebe, no ano de 2002, quando ainda tinha 8 anos de idade. Esse era o novo espaço de dança que estava frequentando, juntamente com o professor Adalberto José Ghislandi, carinhosamente conhecido como "Betinho", e que assim será tratado nesse texto.

Figura 2 - Primeira Apresentação na Academia Somma - Espetáculo de final de ano O Quebra Nozes.

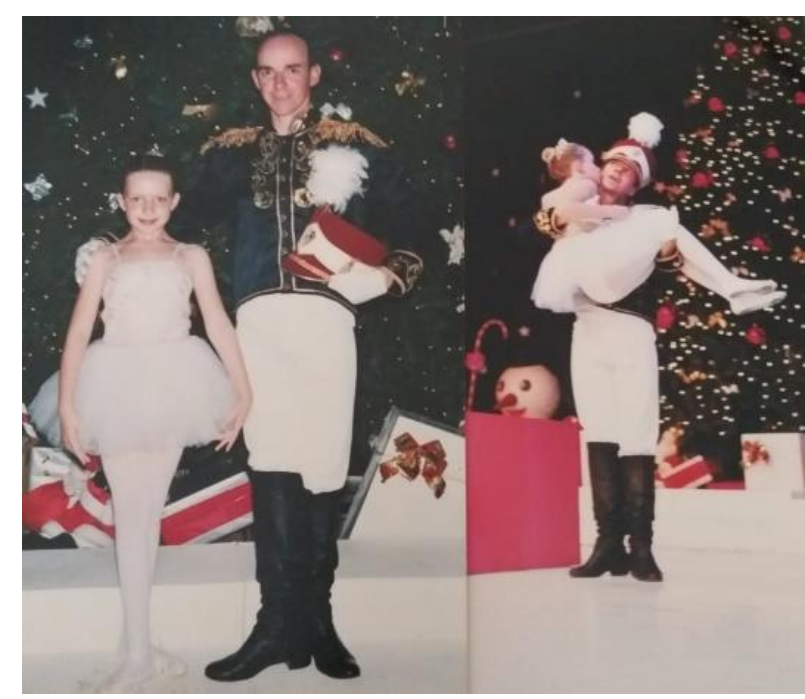

Fonte: acervo pessoal da pesquisadora.

Quando completei 16 anos, a minha professora Neide Aparecida Mattioli Schumacher, aquela da primeira escola de dança, me chamou para fazer aulas com ela novamente, e pelo carinho que tinha por ela e suas aulas, obviamente que não pensei duas vezes e voltei a ter aulas com ela de jazz no Colégio São Luiz. Foi quando me deparei com muitas diferenças entre as novas aulas e 
Revista "O Teatro Transcende" Departamento de Artes - CCEAL da FURB - ISSN 2236-6644 -

Blumenau, Vol. 26, № 1, p. 159 -172 - (2021)

pude perceber certa diferença dentro desta modalidade, como as didáticas dos professores, que eram diferentes, trazendo algo novo e de atualidade. Outra diferença foi na forma de dançar o jazz, que era algo mais linear, sem pausas.

Quando já com meus 22 anos, surge o curso de licenciatura em dança na FURB, isso era no ano de 2017. Logo me inscrevi na primeira turma desde curso e hoje em 2021, sou formada nele. Era um sonho que eu tinha desde pequena. Ao cursar esta licenciatura, pude identificar várias questões relacionadas a dança e ao ensino da dança que eu não tinha percebido ainda mesmo tendo passado por 3 espaços não formais de dança enquanto bailarina, pois eu era a menina que ia para academia dançar e nunca foi provocada a pensar sobre dança. Uma delas é como dança pode estar em todos os nossos movimentos diários, como ela se diferencia entre uma modalidade da outra, ou até mesmo dentro da mesma modalidade, como é caso do jazz que conhecemos muitas vertentes pois já se apresenta várias formas de dançar. E assim surgiram várias questões outras, de onde veio e como começou tudo, e como pode mudar tanto através do tempo.

Frente a este breve relato narrativo, surge a seguinte questão problema deste estudo: Como a dança jazz tem se desenvolvido e se estabelecido na cidade de Brusque (SC)? Pretende-se ressaltar como a dança Jazz teve início em Brusque (SC), os principais professores formadores, os locais que desenvolveram esta dança, qual era a formação destes profissionais, como eles se atualizavam, e as pessoas que eles formaram e que continuam trabalhando com a modalidade na cidade. Acredita-se que este estudo pode ajudar os praticantes e escolas de dança de Brusque, bem como interessados do setor cultural a entenderem mais sobre o desenvolvimento da dança Jazz nessa cidade. Foram criados os seguintes objetivos: Geral - Mapear os atores responsáveis pela construção da história do jazz na cidade Brusque entre os anos 1980 e 2020; e específicos: - Identificar as escolas de dança que iniciaram o trabalho com o jazz na cidade Brusque; - Criar um panorama dos profissionais que trabalham com o jazz na cidade de Brusque entre os anos 1980 e 2020; - Investigar os fatores que transformaram a dança jazz ao longo do tempo na cidade de Brusque.

\section{ALGUMAS HISTÓRIAS SOBRE A HISTÓRIA DA DANÇA JAZZ EM BRUSQUE}

Para organizar algumas das micro-histórias resultantes das entrevistas de cada participante do estudo, estivemos atentos aos relatos sobre a dança jazz em Brusque (SC) desenvolvida por estes profissionais e como ela acontece em cada espaço formativo. Para tal, foram mapeados dez (10) profissionais que trabalham ou trabalharam com a modalidade na cidade no período entre 1980 e 2020, 
Revista "O Teatro Transcende" Departamento de Artes - CCEAL da FURB - ISSN 2236-6644 -

Blumenau, Vol. 26, № 1, p. 159 -172 - (2021)

e na sequência eles foram convidados para participar do estudo. Dois (2) não puderam participar por questões particulares ou incompatibilidade de horários. Com a autorização dos participantes mantivemos nesse texto os seus nomes verdadeiros, o que oportuniza maior visualização e compreensão do entrelaçamento entre as distintas micro-histórias que acontecem em cada um dos espaços formativos em dança na cidade, como se pode verificar no quadro 1.

Quadro 1 - Função de cada Participante.

\begin{tabular}{|c|c|c|}
\hline Participante & Escola/ Studio atual & Função \\
\hline Adalberto José Ghislandi & Academia Somma & Proprietário e professor \\
\hline Elenice Rosélis S. Appel & Studio Slomsky & Proprietária e professora \\
\hline Neide Aparecida Mattioli Schumacher & Studio Anna's & Proprietária e professora \\
\hline Larissa Maria Fischer & Studio Naira Batisti & Professora \\
\hline Naira Batisti & Studio Naira Batisti & Proprietária e professora \\
\hline Júlia Booz Fantini & Studio Anna's & Professora \\
\hline Renata Dal Pizzol Carmignolli & Studio Slomsky e Studio Anna's & Professora \\
\hline Aline Leoni & Studio Slomsky & Professora \\
\hline
\end{tabular}

Fonte: Criação dos autores

Estes participantes foram essenciais para a compreensão do contexto estudado, visto que alguns professores participantes são os percussores da dança em Brusque. Todos estes profissionais começaram sua relação com a dança ainda em suas infâncias. A maioria é natural de Brusque ou se mudaram a algum tempo para a cidade. Como as histórias dos profissionais que participaram deste estudo se cruzam o tempo todo e cada vez mais estão aparecendo profissionais da dança diferentes na cidade, buscamos entender como isso começou no início dos anos 80 e como se desenrolou até 2020. Nesse sentido, buscou-se recolher informações para que se possa ter um maior entendimento das histórias da dança jazz na cidade de Brusque, de forma que os resultados não se cerram nesse estudo e possam se encaminhar para outras pesquisas futuras.

No anseio de ouvir as narrativas destes professores e diretores pedimos que eles relatassem suas vivências e experiências com a dança e obtivemos uma pluralidade das respostas. Utilizamos para esta coleta de dados entrevistas semiestruturada para a obtenção de dados, pois Souza (2019), diz que este tipo de entrevista se caracteriza por permitir que outras questões possam ser geradas em função das respostas obtidas inicialmente pelos entrevistados. A entrevista surgiu como possibilidade para obter 
informações sobre o que os participantes sabem, almejam, sentem, vivem ou expressam sobre os seus processos e relações com a dança jazz.

Depois de realizadas as entrevistas presencialmente, cada uma delas foi transcrita na íntegra. Foi um processo trabalhoso, mas muito importante para os pesquisadores, por poderem acessar os diferentes contextos a partir das visões dos participantes e perceber como a história é complexa, cheia de interrelações umas com as outras.

\section{INTERPRETAÇÃO E ANÁLISES DOS DADOS}

A análise suscitada dos dados obtidos nas entrevistas foi organizada em categorias. Adverte-se que a separação nessas categorias de análises responde a necessidades meramente organizativas, pois trata-se de realidades profundamente articuladas entre si por ser Brusque uma cidade pequena e os profissionais circularem constantemente nos espaços de ensino de dança. Esta disposição é o resultado de uma leitura exaustiva das transcrições das entrevistas realizadas e de exercícios descritivos e analíticos da realidade pesquisada.

Os entrevistados mostraram grande interesse em responder as perguntas, e ficaram extremamente envolvidos com o tema escolhido para ser descrito aqui. Durante as entrevistas percebemos a emoção dos professores ao contarem um pouco de suas memórias e histórias por onde eles percorreram o seu caminho na dança.

\footnotetext{
Essas memórias e fragmentos da dança, mesmo sendo bastante singulares, são contextos de um passado que é recuperado no presente e que tem o compromisso de ampliar a possibilidade de construções de novos conhecimentos críticos desta realidade. Respeitando a diversidade das estéticas e experiências, propôs-se janelas para a imaginação e as interpretações. (FIGUEIREDO e RIBEIRO, 2017, p. 118.)
}

Eles nos relataram ainda que estão sempre dispostos a trazer novas experiências corporais e artísticas para dentro de suas aulas. Identificamos que foi na década de 1980 que se iniciou o ensino da dança jazz na cidade, constituindo um cenário importante na formação de professores e bailarinos brusquenses. Para maior compreensão do leitor sobre os diferentes espaços em que se ensina a dança jazz em Brusque, formulamos uma linha do tempo para identificar melhor as passagens de alunos e professores pelas academias e studios citados. Nas figuras 1 e 2, pode-se identificar acima da linha 0 nome de cada espaço formativo em dança em Brusque e logo abaixo o nome dos professores que trabalhavam ou trabalham com a dança. Abaixo da linha do tempo, apresentamos os alunos que depois passaram a ser professores nesses espaços ou ainda em outros espaços. 
Figura 1 - Linha do tempo $1^{\mathrm{a}}$ parte

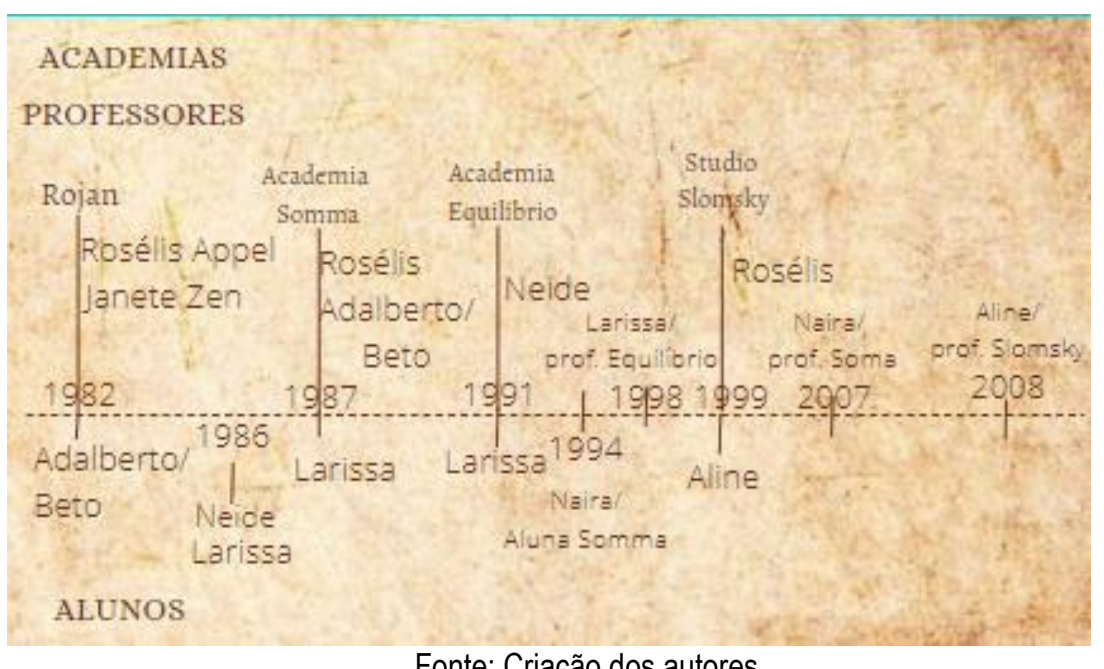

Fonte: Criação dos autores

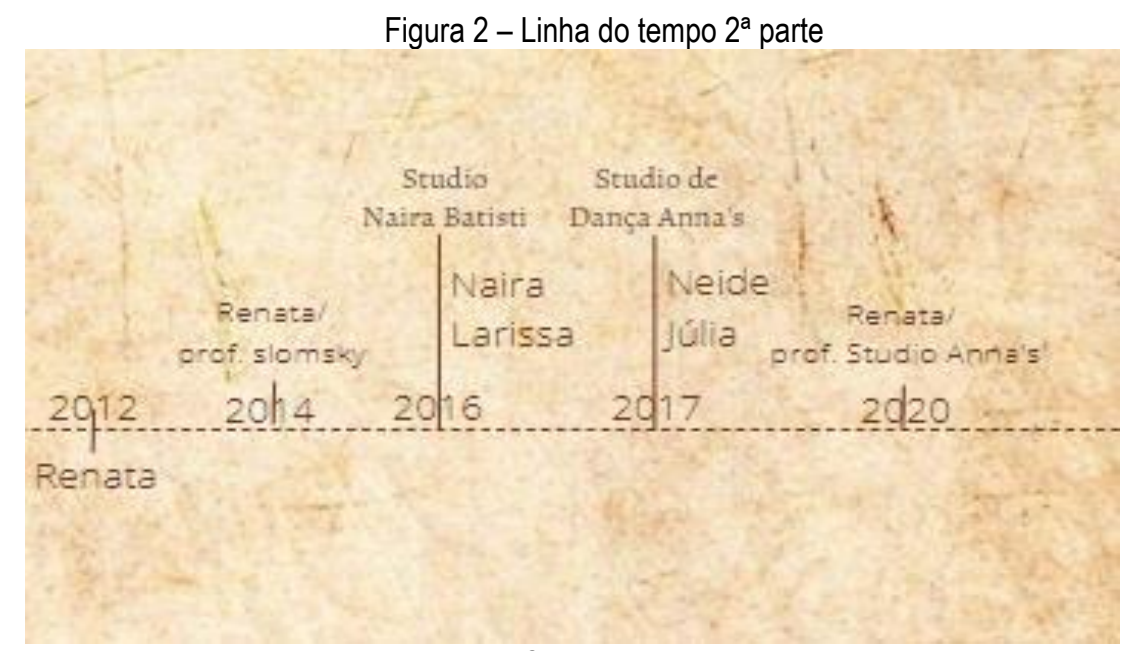

Fonte: Criação dos autores

Apresentamos agora individualmente as análises resultantes das categorias dos dados.

\section{ESPAÇOS PARA A REALIZAÇÃO DO JAZZ}

Nessa categoria começamos a contar as histórias de academias e professores de dança que são "micro histórias cheias de vazios, de buracos, que por vezes se mantiveram no experimentalismo, no anonimato, na simples vivência e também no esquecimento". (FIGUEIREDO e RIBEIRO, 2017. p.118). Começamos a desvendar danças e descobrir mais sobre cada um, que com seu estilo próprio e muito paixão pela dança conseguiu um lugar na cidade de Brusque. 
Revista "O Teatro Transcende" Departamento de Artes - CCEAL da FURB - ISSN 2236-6644 Blumenau, Vol. 26, № 1, p. $159-172-$ (2021)

Vamos apresentar os espaços para o ensino da dança em Brusque (SC), onde aconteceram os primeiros passos de dança jazz e por onde começou esta modalidade na cidade. Criamos esta por ser um eixo que abraça todas as outras categorias, já que a maioria dos entrevistados da primeira geração de professores de Brusque (SC) passaram por uma única academia nessa cidade quando iniciaram suas histórias com a dança.

A Academia Rojan foi fundada em 1982 por Janete Zen e Romilda Muller, onde o nome se dá por junção das primeiras sílabas dos nomes das proprietárias. A academia era instalada no centro da cidade de Brusque e oferecia para comunidade aulas nas modalidades de jazz e dança contemporânea. Seus professores eram a Janete Zen e a Elenice Rosélis S. Appel, conhecida no meio artístico de Brusque como Rosélis. Seus alunos que continuaram os estudos em dança eram Adalberto José Ghislandi (Betinho) e Neide A. Mattiolli Schumacher. Já podemos identificar uma relação com a origem da dança jazz, onde os dois alunos citados, mais tarde se tornam professores de dança na cidade e abriram suas próprias academias.

Estas duas professoras da academia Rojan foram as que começaram a trilhar o trabalho com dança em Brusque, e consequentemente, a escrever a história da dança na cidade. Seu trabalho fez com que alguns de seus alunos (Betinho, Larissa e Neide) seguissem no universo da dança. Leal (2017, p.9) diz que "como uma semente que germina continuamente outras tantas danças e outros modos de expressar". As professoras ao passar seus conhecimentos para seus alunos passam a germinar um saber, o saber de dançar.

Mais tarde, começam a aparecer novos espaços para o ensino de dança em Brusque (SC), como a Academia Somma (1978), como a Academia Equilibrio (1995) e o Studio Slomsky (1999), transformando a dança de Brusque e modernizando-a a cada década que se passava, criando novos profissionais e amantes da dança.

A academia Somma surgiu em 1987 com aulas de jazz e dança contemporânea sob a direção da administradora Romilda Muller. Betinho assumiu a função de professor juntamente com a professora Rosélis nessa academia. Betinho comenta que ele e a Rosélis lecionaram durante 10 anos juntos, "[...] a academia Rojan tinha fechado e a Rosélis, que era professora também da Rojan, foi convidada para trabalhar na academia Somma. Então trabalhávamos eu e a Rosélis. Durante 10 anos trabalhamos nós dois." A academia Somma inicialmente era situada no bairro Maluche e hoje fica situada no centro da cidade de Brusque.

Em janeiro de 1999, Rosélis abre a porta de seu novo studio chamado Slomsky, situado no bairro Jardim Maluche, oferecendo aulas de dança clássica, jazz e dança contemporânea. Hoje em dia o studio 
Revista "O Teatro Transcende" Departamento de Artes - CCEAL da FURB - ISSN 2236-6644 -

Blumenau, Vol. 26, № 1, p. 159 -172 - (2021)

ampliou o leque de ofertas e conta com aulas de Ballet Clássico, Dança de Salão, Dança Contemporânea, Hip hop, Jazz Dance, Groovy, Pop Dance, Axé Dance.

Neide, aos 17 anos começou a atuar como professora de dança. Ministrava aulas de jazz no salão da igreja do bairro Guarani e logo em seguida abriu sua primeira academia chamada Equilíbrio em 1995 no mesmo bairro, onde abriu as portas da dança para muitas meninas da região do bairro e da cidade vizinha Guabiruba. Em depoimento Neide afirma:

Eu trabalhava na têxtil Renaux, e só a noite eu dava aulas ali no Guarani. Só que eu não era feliz com isso, eu queria só a dança, então comecei a trabalhar só com a dança, abri mais turmas durante o dia, e surgiu que comecei a querer a academia, foi onde começou a academia Equilibrio. (Neide, 2021).

Após uma pausa de cinco anos para a maternidade iniciada no ano de 2003, Neide recomeçou a lecionar aulas de dança, mas desta vez no Colégio São Luiz, e em 2017 criou o seu novo estúdio, 0 Studio de Dança Anna's.

Naira Batisti, começou aos 5 anos como bailarina na academia Somma. Aos 20 anos começou a lecionar nessa mesma academia e depois de formada em educação física, criou seu studio de dança chamado Naira Batisti localizado na Rodovia Antonio Heil, no ano de 2016. Naira chamou a professora Larrisa para ser uma de suas professoras do studio. Mais uma vez as histórias se cruzam numa linda linha desenhada com o tempo.

\section{PROFISSIONAIS QUE TRABALHAM COM A DANÇA JAZZ}

Para os professores entrevistados, muitas informações sobre a dança Jazz são encontradas por eles em cursos livres (na própria cidade e em festivais), nos quais tentam observar e descobrir metodologias novas para trabalharem com seus alunos, conforme comenta Rosélis:

Eu fui passando por vários profissionais, como Carlota Portela, Eva schul, Eliane Fetzer, cheguei a fazer aula com uma bailarina da Martha Graham, uma das pupilas dela. Quanto mais vivência você tiver melhor, eu sempre incentivo os alunos a fazer outros cursos, a viajar, você não pode ficar nas 4 paredes. Quanto mais vivência e mais técnica, e poder absorver lá da fonte, tentar chegar o mais perto do percussor. É muito bom.

A professora ressalta que mesmo com algumas dificuldades, no início dos anos 80 e 90 os professores de dança de Brusque conseguiram fazer bons cursos que fortalecia a formação deles, e que como resultado, deu uma grande visibilidade e procura na cidade até os dias de hoje. Dentre os nomes dos profissionais que eram procurados para fazer cursos pelos entrevistados destacamos alguns nomes como: Roseli Rodrigues (SP), Eva Schul (RS) e Carlota Portela (RJ). 
Para Neide e Betinho era muito difícil sair da cidade, mas sempre que podiam iam para Curitiba (PR) e Joinville (SC). Neide relata: "Ílamos para a jornada paranaense, fizemos aulas de dança de tudo que tinha, aulas de street com o Marcelo Cirino, cursos de Joinville também. Sempre fiz muitos cursos". Pode-se perceber a partir desta fala, um processo de hibridação, pois os professores de jazz passaram a fazer cursos de street dance, o que pode ter resultado na oferta de aulas em Brusque de street jazz, o que se foi muito aceito em todos os espaços de dança da cidade.

Hoje em dia, como o avanço de nossa relação com a tecnologia e internet, os professores acreditam que os cursos ofertados são de fácil acesso, onde conseguem encontrar cursos online e gratuitos, de várias modalidades de dança e com metodologias diferenciadas. A professora Júlia comenta: "Estou acabando a faculdade de educação física agora e estou fazendo os cursos online. Agora na pandemia tem muita oportunidade de cursos online. Eu prefiro os cursos presenciais. Mas a facilidade e o custo dos online é muito mais viável". Para Renata, a internet ajuda bastante em suas pesquisas. "Eu fiz alguns cursos, com a Tati Sanchis em São Paulo. Eu acompanho muito, assisto muito conteúdo dela assim [sic]. E é mais auto ditada assim, eu procuro muita coisa, estudo muita coisa, eu procuro sempre pesquisar coisas. Sempre mais na internet". A professora Naira, na mesma direção das outras professoras, gosta de pesquisar na internet para ter novas ideias, mas prefere os cursos presenciais. Para a professora Larissa, os livros são de grande ajuda, mas no momento procura conhecimento através da internet por ser um acesso rápido.

Eu sempre fui muito inquieta, então eu fazia muitos cursos, procurava falar com algum professor
de fora, porque eu queria algo diferente. Eu fui me preparando, na verdade acho que sempre fui
e estou sempre me preparando. Por exemplo nesta pandemia, teve muito oportunidade de
cursos online gratuito ainda. Logico não é nada comparado com o presencial, porque trocamos
muita informação com quem está fazendo o curso, não só com o professor. Mas abriu um leque
muito grande para buscarmos algo diferente. Acho que sempre temos que estar estudando.
(Naira, 2021)

Podemos identificar que os professores entrevistados estão sempre em busca de novos conhecimentos e novas metodologias de ensino pois acreditam que a dança de ontem não é a mesma de hoje, da mesma forma que os alunos de hoje já não são os mesmos que os de ontem. Acreditam ainda que estar disposto a mudanças, a querer evoluir, é muito importante para si e para os alunos, querer sempre aprender com os outros e com os próprios alunos, fazem um excelente professor. Segundo Morales (2006), "quando se trata de professores queridos e aceitos por seus alunos, estes podem aprender com esses professores muito mais do que o professor conscientemente pretende ensinar". Mesmo não aparecendo nas entrevistas, podemos perceber o quanto são amados e queridos pelos seus alunos. Nossos professores entrevistados dançam desde criança ou adolescentes, apreciam 
a arte da dança desde muito cedo, e sempre foram em busca de seu sonho, que era trabalhar com a dança.

A dança jazz nessa na perspectiva dos entrevistados vai estar sempre em constante renovação. Muitos dos entrevistados relatam que ele evoluiu muito desde que começaram, por isso a importância de pesquisar e fazer cursos para estar atualizados, e se permitir dialogar com outras modalidades de dança. Para os entrevistados, o jazz está sendo uma mistura de ritmos e modalidades. 0 jazz está se renovando e criando vertentes a partir das já existentes como se pode ver nos depoimentos.

Eu acho que é bem isso. O pessoal querer pesquisar um pouco mais essa junção, que o corpo podia fazer, e o que cada um podia agregar de suas vivencias no seu jazz, para não ficar uma coisa quadrada. As 51 pessoas querendo explorar um pouco mais o jazz, esta mistura. (Renata, 2021)

Olha, quando eu aprendi era aquele jazz, mas engessado, mas um aeróbico, hoje em dia está mais amplo, está mais misturado. Por isso acho que ninguém mais se entende, vamos falar assim (risos). Hoje em dia abriu muito, a internet acaba vedo coisas de tudo quando lugar. Antigamente era uma pirueta em pace com a mão no peito, e hoje em dia tem piruetas de tudo qualquer tipo. (Neide, 2021)

Pode-se perceber que a dança jazz na cidade de Brusque abriu muitos espaços para várias pessoas trabalhar e viver dela, cada geração que está vindo está conseguindo ganhar espaço e abrir seus próprios studios e academias de dança gerando empregos e diversidade de modalidades na área.

Verificou-se que a história do jazz na cidade de Brusque (SC) parte de uma geração de bailarinos e professores que nos anos 80 queriam se expressar e ter liberdade de movimentos, muitas vezes gerando moda e oportunizando a renovação na forma de dançar, conforme são apresentados nos espetáculos de final de ano de cada um dos espaços de ensino de dança. Como consequência, mudanças constantes, que vão desde 1980 até a atualidade, tendo influências de pessoas com as quais os professores faziam cursos, de suas trajetórias pessoais, de pesquisas e histórias vindas de fora da cidade ou de dentro, e até mesmo dos alunos e do que a comunidade de Brusque aceitava. Os entrevistados acreditam que vai ser assim por um bom tempo, e logo a dança jazz poderá influenciar outras modalidades também.

\section{Metodologias usadas}

Os professores entrevistados nos relataram sem muita objetividade como organizam e ministram suas aulas, onde fazem sua formação continuada e quais metodologias eles seguem. Os professores dizem que conseguem passar seus ensinamentos para seus alunos, dessa forma há uma troca de experiências e vivências no cenário da dança jazz na cidade. Os professores atuais, da terceira geração, 
Revista "O Teatro Transcende" Departamento de Artes - CCEAL da FURB - ISSN 2236-6644 -

Blumenau, Vol. 26, № 1, p. 159 -172 - (2021)

aprenderam e aprendem muito com os seus antigos professores, fazendo com que ocorram trocas constantes.

Com a variedade de vertentes do jazz, pode-se dizer que existe uma grande possibilidade autonomia de cada professor no seu fazer, quanto estrutura, criação, pesquisa, e difusão cultural. Há portanto, espaço para criar coreografias diferentes, lentas, rápidas, com giros e saltos ou não. Ele se expandiu muito rápido e de várias formas por vários canais de comunicação. Expandiu-se de várias formas, dentre elas: nos filmes, "night-clubs", nos palcos da Broadway e principalmente televisão" como aponta (GIOVANETTI, 1983)

Alguns dos nossos entrevistados têm formação em outras áreas de conhecimento como em pedagogia e educação física. Eles buscam levar para suas aulas vários conhecimentos e atividades relacionadas com a dança a partir de suas formações. A professora Júlia Fantini comenta: "tinha bastante coisa que eu aprendia na faculdade e que eu aplicava bastante, as partes que os professores ensinavam de dar aula, além da Neide sempre me ajudando". Para a professora Neide Schumacher que é formanda em pedagogia, ela comenta que: "Como eu fiz pedagogia, ela me deu embasamentos para saber lidar com as pessoas, saber como ensinar, saber explicar o passo a passo". Para a professora Larissa, a faculdade de Educação Física também ajudou muito. "Como eu fazia educação física, tinha bastante coisa em dança também né? Então tinha bastante coisa e daí eu fui colocando um pouquinho de teoria." E a professora Naira entrou para a educação física para ter alguma relação com a dança, visto que não tinha faculdades de dança no estado na época. "Na época não tinha faculdade de dança aqui, acho que só em Curitiba, Rio Grande do Sul e no Rio de Janeiro, pelo menos que eu sabia. E eu era muito apegada na família, eu não queria mudar de cidade para fazer faculdade. Então comecei a fazer educação física para seguir na área da dança”.

Todos os professores entrevistados têm conhecimento em suas áreas de atuação (jazz), suas estratégias aplicadas em aula, fazem com que muitos alunos retornam para as academias, fazendo com que permaneçam por anos na arte da dança. Metodologias muitas vezes inovadora e de reconhecimento de seus praticantes, fazendo ter harmonia e alegria dentro da sala de aula.

Os professores aprendem e tentam passar de uma maneira diferente seus aprendizados conforme os perfis de cada turma. A professora Neide relata em sua entrevista: "As aulas, cursos, que eu fazia eram para mim, como professora, e através da minha criatividade eu adaptava para minhas aulas, eu usava muito bambolê, pompons, eu ia atras, o que eu via que os olhinhos das meninas brilhavam eu usava". 
Revista "O Teatro Transcende" Departamento de Artes - CCEAL da FURB - ISSN 2236-6644 -

Blumenau, Vol. 26, № 1, p. $159-172-$ (2021)

Eles acreditam que são capazes de auxiliar os estudantes/bailarinos no processo de transformação, e estudantes/bailarinos são capazes de transformar professores, isso só depende da relação estabelecida entre eles, aprendendo como ensinar de forma didática e afetuosa.

\section{CONSIDERAÇÕES FINAIS}

Terminar este trabalho colocou-nos num exercício de compreensão e organização dos dados e nos fez reconhecermos a importância deste material para a história da dança jazz em Brusque (SC).

Fazer este foi ao mesmo tempo um momento mágico e transformador para os pesquisadores, pois acessamos lugares que não seria possível se não fosse por meio das entrevistas, como conhecer melhor os contextos das pessoas que trabalham com o jazz, as redes que ligam uns aos outros. Isso, trouxe um conhecimento maior sobre a dança jazz realizada na cidade de Brusque (SC), a partir de um olhar sensível para cada história contada por cada entrevistado.

Procurou-se organizar as narrativas da dança jazz da cidade de Brusque (SC), contribuindo para 0 acervo da história em dança da cidade, visto que não há nenhum documento descritivo sobre o assunto até o momento. Não se tratou em somente identificar as escolas que trabalham com a dança jazz, mas em conhecer um pouco mais sobre as suas histórias e seus professores percussores e como chegamos até aqui com esta modalidade.

Foi identificado que nos anos 80 as duas escolas onde o trabalho com 0 jazz foi iniciado na cidade foram a escola Rojan (criada em 1982) e logo a Somma (criada em 1987). E dessas escolas se formaram outros professores e amantes da dança, sendo criadas na cidade outras escolas, das quais quatro escolas ainda oferecem aulas de jazz atualmente: Somma, SlomSky, Studio de Dança Anna's e Studio de dança Naira Batisti. Vale ressaltar que todas estas escolas também trabalham com o ensino de outras modalidades de dança, para além do jazz, fazendo com que a trocas de experiência entre os professores e alunos sejam constantes, criando possibilidades criativas a partir do encontro dos corpos e movimentos para a modalidade de jazz.

Ao tentar criar um panorama dos profissionais que trabalham com o jazz na cidade de Brusque entre os anos 1980 e 2020, identificamos que os profissionais começaram em aulas de dança nas academias citadas ainda criança, exceto o professor Betinho que começou a dançar na sua adolescência e a Rosélis que veio de São Paulo (SP) para dar aulas na cidade. Estes dois profissionais além de serem uns dos percussores do ensino da dança jazz em Brusque (SC) seguem até 2020 trabalhando na área. Os outros entrevistados começaram seus estudos a partir deles que seriam a 2 geração, e assim conseguimos obter entrevista com a 3 geração. 
Quanto aos fatores que transformaram ou modificam a dança jazz ao longo do tempo na cidade de Brusque, identificamos que existe a presença de 2 fatores principais. $O$ primeiro é que as pessoas de Brusque (alunos de dança) gostam de experimentar coisas novas e se expressar de uma maneira diferenciada e por isso procuram novidades na forma de dançar, pois não tem a ambição de formar bailarinos profissionais, e sim fazer com que os alunos se sentam felizes nas aulas e queiram voltar para a academia ou o studio. $O$ segundo fator, é a internet e o modismo, que fez com que 0 jazz virasse um produto a ser vendido e consumido e nesse sentido as academias e studios precisam de alunos para sobreviver. Com isso, vendem muito mais modismo, que acaba transformando e criando modalidades diferenciadas e fugindo do jazz tradicional em sua primeira forma de expressão.

\section{REFERÊNCIAS}

GIOVANETTI, N. Pesquisa: história do jazz-dance. [s.i.], 1983 Mimeografado.

LEAL, Patrícia. Em fluxo: poesia, prosa, teoria em dança na contemporaneidade. Natal, RN. Ed. Caule de Papiro, 2017.

MICHAELIS Dicionário Brasileiro da Língua Portuguesa. São Paulo: Melhoramentos Ltda, 2020. Disponivel em: https://michaelis.uol.com.br/. Acesso em: 18 abr. 2020.

MORALES, Pedro. A relação professor-aluno: o que é, como se faz. São Paulo. Edições Loyola. 2006.

RIBEIRO, Luciana Gomes; FIGUEIREDO, Valéria Maria Chaves de. OLHARES PRA DANÇA: HISTÓRIAS E AFETOS DA DANÇA CÊNICA GOIANIENSE 1970-2000. Revista de Teoria da História, Goias, v. 18, n. 2, p. 116-129, dez. 2017.

SOUZA, Marco Aurelio da Cruz. A dança popular no processo de formação do bailarino clássico e contemporâneo: estudo sobre a Escola do Teatro Bolshoi do Brasil. 2019. 292 f. Tese (Doutorado) Universidade de Lisboa Faculdade de Motricidade Humana, Lisboa, 2019. 